\title{
ISOLAMENTO DE ARQUEAS E BACTÉRIAS ANAERÓBIAS EM MEIOS RESIDUAIS DE CURTUMES
}

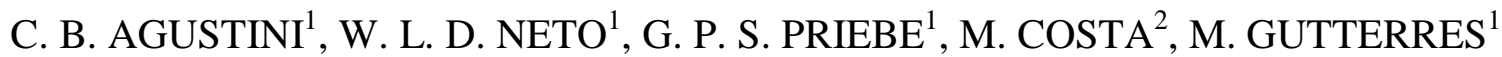 \\ ${ }^{1}$ Universidade Federal do Rio Grande do Sul, Departamento de Engenharia Química \\ ${ }^{2}$ Universidade Federal do Rio Grande do Sul, Instituto de Ciências Básicas da Saúde, Departamento \\ de Microbiologia, Imunologia e Parasitologia, \\ E-mail para contato: caroline.agustini@ufrgs.br
}

\begin{abstract}
RESUMO - A indústria coureira tem grande importância econômica. Entretanto, a sobra de resíduos do processo e a crescente importância da geração de energia a partir de fontes renováveis faz com que seja necessário estudar formas de biodegradação dos resíduos e gerar energia a partir disso. O presente trabalho tem como objetivo realizar o isolamento e a identificação dos procariotos anaeróbios, alguns com potencial para a produção de biogás quando degradam resíduos de curtume. Para tanto, foram realizados testes em biorreatores de bancada contendo lodo de estação de tratamento de efluente de curtume e farelo de couro wet-blue e a geração de metano foi medida periodicamente, onde a produção máxima foi na sexta semana de experimento com média de $10 \mathrm{~mL}$ de geração diária de gás. Quando a produção de metano foi máxima, foi feita a coleta destes microrganismos anaeróbios para subsequente isolamento e identificação.
\end{abstract}

\section{INTRODUÇÃO}

A crescente importância da geração de energia a partir de fontes alternativas devido às altas taxas de poluição e sérios impactos ambientais causados pelas fontes tradicionais tornou as fontes de energias renováveis uma alternativa muito estudada atualmente. A geração de energia a partir de fonte renovável permite a reciclagem da matéria existente na natureza, renovando-a continuamente. São exemplos de energia renovável: recursos hídricos, energia eólica, energia solar, geotérmica, biomassa, entre outras. Define-se como biomassa todo recurso renovável proveniente de matéria orgânica, animal ou vegetal, sendo que a biomassa pode ser utilizada na produção de energia.

A indústria coureira tem grande importância onde está inserida. O Brasil é um dos maiores produtores mundiais de couro sendo responsável por $13 \%$ da produção mundial. Entretanto, o processo de curtimento gera quantidades significativas de resíduos sólidos e líquidos com altos teores de poluentes, devido aos produtos tóxicos usados durante o processo, tais como, sulfato básico de cromo e sulfeto de sódio (DETTMER, 2012).

Em um curtume, cada pele processada gera, em média, $12 \mathrm{~kg}$ de lodo residual com características variadas devido ao tipo de pele, à tecnologia no processamento, ao sistema empregado na estação de tratamento de efluente - ETE, entre outros fatores (SOUZA, 2009). Os lodos de ETEs 


\section{9 a 22 de outubro de 2014 \\ Florianópolis/SC}

são, em sua grande maioria, destinados a aterros de resíduos industriais perigosos - ARIPs. Aterros são obras de engenharia projetadas sob critérios técnicos, cuja finalidade é garantir a disposição dos resíduos sólidos sem causar danos à saúde pública e ao meio ambiente. Os ARIP's podem ser descritos como grandes reatores anaeróbios que geram, a partir da estabilização da matéria orgânica, os seguintes subprodutos: gases $\left(\mathrm{CH}_{4}, \mathrm{CO}_{2}, \mathrm{NH}_{3}\right.$, entre outros), líquidos (chorume) e, ainda, matéria sólida remanescente (BIDONE, 2007).

A digestão anaeróbia é um processo biológico onde o consórcio de diferentes microrganismos, na ausência de oxigênio molecular, promove a transformação de compostos orgânicos complexos em produtos mais simples, tais como metano (QUADROS, 2009). O biogás é o produto da decomposição, pelas arqueas, de matéria orgânica proveniente de diferentes fontes, como aterros sanitários, biodigestores e resíduos animais.

A partir desses conceitos, esse trabalho propõe incubar lodo proveniente de aterros de curtumes em biorreatores de bancada com a finalidade de coletar e isolar os microrganismos que apresentam potencial de produzirem biogás.

\section{MATERIAIS E MÉTODOS}

\subsection{Biorreatores em Escala de Bancada}

O cultivo dos microrganismos produtores de metano capazes de degradar resíduos de curtumes foi realizada em biorreatores de bancada. Esses biorreatores são feitos de vidro, com volume útil de $350 \mathrm{~mL}$, e foram mantidos em um banho termostático a $35^{\circ} \mathrm{C}$. Eles possuem duas válvulas de abertura, uma superior, utilizada para a medida de volume de gás produzido, e uma lateral, utilizada para a retirada de amostras para análise cromatográfica.

A montagem dos 6 biorreatores, baseada nos resultados obtidos por Priebe et al. (2013), foi realizada adicionando-se, em cada biorreator, $1 \mathrm{~g}$ de farelo de rebaixamento (ajuste de espessura) de couro wet-blue (couro curtido com cromo), como fonte de matéria orgânica a ser degradada, $25 \mathrm{~mL}$ de lodo ativado adensado, coletado de uma estação de tratamento aeróbio de um curtume que utiliza sais de cromo como agente de curtimento e, para assegurar condições favoráveis para o crescimento dos microrganismos, $250 \mathrm{~mL}$ uma solução de nutrientes, descrita por Dettmer et al. (2012).

Os experimentos foram realizados em duplicata, onde a diferença entre eles era a forma de armazenamento do lodo, por aproximadamente 6 meses antes do início dos experimentos. Nos biorreatores 1 e 2, o lodo foi armazenado em temperatura ambiente e sem vedação para a entrada de $\mathrm{O}_{2}$. Nos biorreatores 3 e 4, o lodo foi armazenado na geladeira e com vedação para a entrada de $\mathrm{O}_{2}$. Nos biorreatores 5 e 6, o lodo foi armazenado em temperatura ambiente, com vedação para a entrada de $\mathrm{O}_{2}$ e $100 \mathrm{~g}$ de colágeno hidrolisado foram previamente adicionados em aproximadamente $1 \mathrm{~L}$ de lodo como fonte de material orgânico prontamente disponível. 


\subsection{Medidas de Volume de Gás Gerado}

O volume total de gás gerado foi medido diariamente através de um aparato (Figura 1) baseado no deslocamento de volume de água através de equalização de pressões.

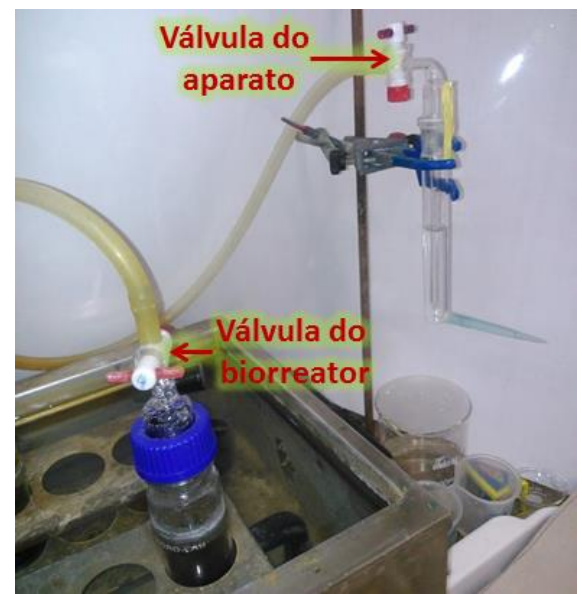

Figura 1 - Disposição dos instrumentos para realização da medida de volume total de gás gerado.

Para a realização da medida, a mangueira era conectada no biorreator na sua abertura superior. A válvula do aparato era aberta para aliviar a pressão remanescente, sendo então a água que saia nesse momento descartada. A válvula do biorreator era aberta liberando um volume de água pelo aparato equivalente ao volume de gás gerado no biorreator. Esse volume de água era pesado e convertido em volume através da massa específica da água na temperatura da sala no momento da medida.

\subsection{Análise dos Gases Gerados por Cromatografia Gasosa}

Para a determinação da composição dos gases gerados nos biorreatores, utilizou-se um cromatógrafo gasoso (GC) equipado com um detector de condutividade térmica (TCD). Duas colunas empacotadas foram utilizadas, Porapak Q e Peneira Molecular. A primeira, Porapak Q (80-100 mesh), determinava a fração entre ar $\left(\mathrm{O}_{2}+\mathrm{N}_{2}\right)$, metano $\left(\mathrm{CH}_{4}\right)$ e dióxido de carbono $\left(\mathrm{CO}_{2}\right)$. A outra, Peneira Molecular (80-100 mesh), determinava a proporção entre $\mathrm{O}_{2}$ e $\mathrm{N}_{2}$ no ar. As condições de análise, são descritas por Priebe et al. (2013). As medidas foram realizadas semanalmente para monitoramento da produção de gás.

\subsection{Coleta dos microrganismos}

Após 118 dias de experimento, amostras foram coletadas. Como os microrganismos de interesse, os metanogênicos, são estritamente anaeróbios (Whitman, 2006), todo o procedimento de coleta foi planejado de forma que a sua exposição ao ar atmosférico fosse mínima.

Primeiramente, o biorreator de maior produção de biogás, reator 2, foi aberto e foram retiradas alíquotas de 0,2 $\mathrm{mL}$ do líquido e 0,2 $\mathrm{mL}$ da fase sólida. Cada uma das alíquotas, tanto do líquido 
quanto do sólido, foram colocadas em frascos tipo penicilina com $20 \mathrm{~mL}$ de uma solução de minerais (Whitman, 2006). Foram realizadas 4 diluições-centesimais. De cada uma das diluições, transferiu-se uma alíquota de 0,1 mL para o meio anaeróbio (Whitman, 2006), em duplicata, também dispostos em frascos tipo penicilina com $20 \mathrm{~mL}$ cada, previamente dissolvidos e mantidos a $58^{\circ} \mathrm{C}$. Algumas modificações foram feitas: foi utilizado ágar $2 \%$, retirada a solução de sulfeto, e o meio foi disposto inclinado. Não foram adicionado gases $\left(\mathrm{H}_{2}, \mathrm{~N}_{2}\right.$ e $\left.\mathrm{CO}_{2}\right)$ neste experimento.

Com exceção da extração feita do sólido precipitado com uma agulha longa, agulha Raquidiana BD Spinal TM (código: 405211), todas as transferências de soluções foram feitas o mais rápido possível com auxílio de seringa de insulina, com agulha simples. Todas as inoculações foram feitas com os frascos fechados (tampa de borracha), perfurando-se a borracha, com o meio de cultura ainda líquido.

Após cada diluição, os frascos eram homogeneizados lentamente e posicionados na posição inclinada, até solidificação. A incubação foi feita a $35^{\circ} \mathrm{C}$, mesma condição de temperatura dos biorreatores.

Para controle do ensaio utilizou-se a Escherichia coli (ATCC 10145) e Pseudomonas aeruginosa (cepa ambiental) como controle positivo e negativo para anaerobiose respectivamente.

\section{RESULTADOS E DISCUSSÕES}

\subsection{Volumes de gases gerados}

Volume total de gás gerado: O volume de gás total gerado, medido por 118 dias, é mostrado na Figura 2.

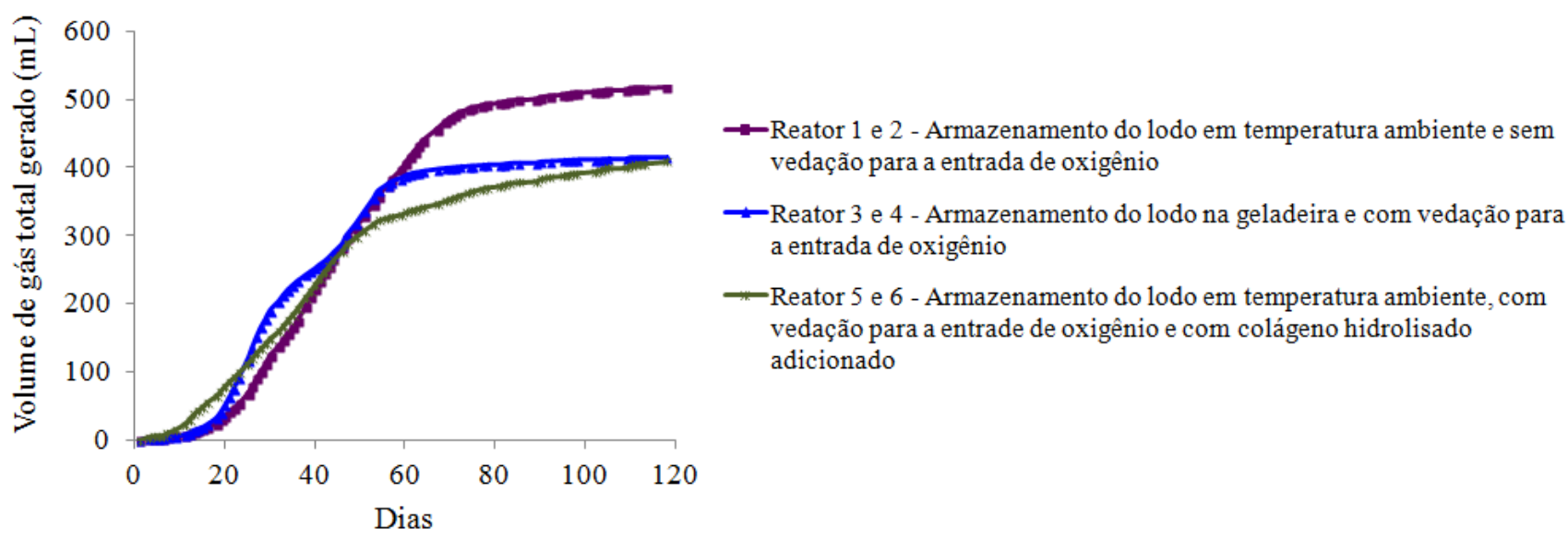

Figura 2 - Média do volume total de gás gerado de cada duplicata.

O comportamento das curvas é característico de crescimento em meios fechados e os valores obtidos foram dentro do esperado, quando comparados com os valores obtidos por Priebe, et al. 
(2013). A duplicata 1 e 2, com lodo armazenado em temperatura ambiente e sem vedação para a entrada de $\mathrm{O}_{2}$, que teve a maior produção de gás, mostrou um comportamento atípico do reator 1 , que teve um crescimento inicial muito lento, porém um crescimento subsequente muito acelerado, de forma que, ao fim do experimento, os dois reatores obtiveram quantidades semelhantes de volume total de gás gerado. A duplicata 3 e 4, com lodo armazenado na geladeira e com vedação para a entrada de $\mathrm{O}_{2}$, segunda a ter maior produção, também mostrou um comportamento atípico no reator 4, que, ao final do experimento, cessou a produção muito antes que o 3, devido, provavelmente, a alguma falha na sua montagem. Entretanto, mesmo com o desempenho baixo do reator 4, a média dessa duplicata ainda ficou maior que a duplicata 5 e 6, com lodo armazenado em temperatura ambiente, com vedação para a entrada de $\mathrm{O}_{2}$ e com colágeno hidrolisado adicionado, que foi a mais similar entre as duplicatas e a que menos produziu gás.

Cromatogramas: Exemplos de cromatogramas gerados para uma amostra no início do experimento são mostrados na Figura 3. Eles mostram grande quantidade de ar dentro do biorreator e pouca quantidade de metano e gás carbônico.
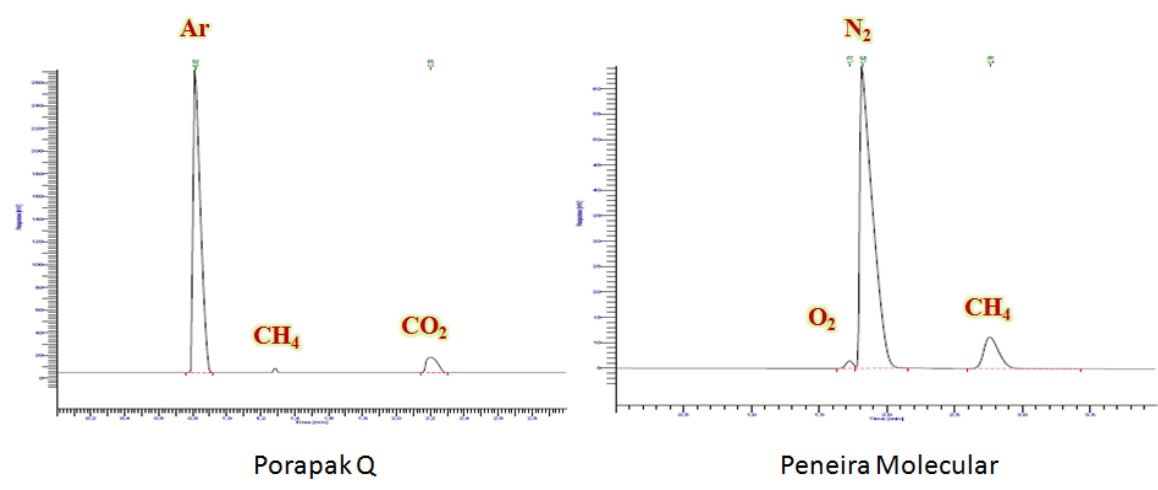

Figura 3 - Exemplos de cromatogramas gerados na segunda semana de experimento em $\mu \mathrm{V}$ x s.

Exemplos de cromatogramas gerados para uma amostra no final do experimento são mostrados na Figura 4. Eles mostram uma quantidade ínfima de ar e grande quantidade de metano.
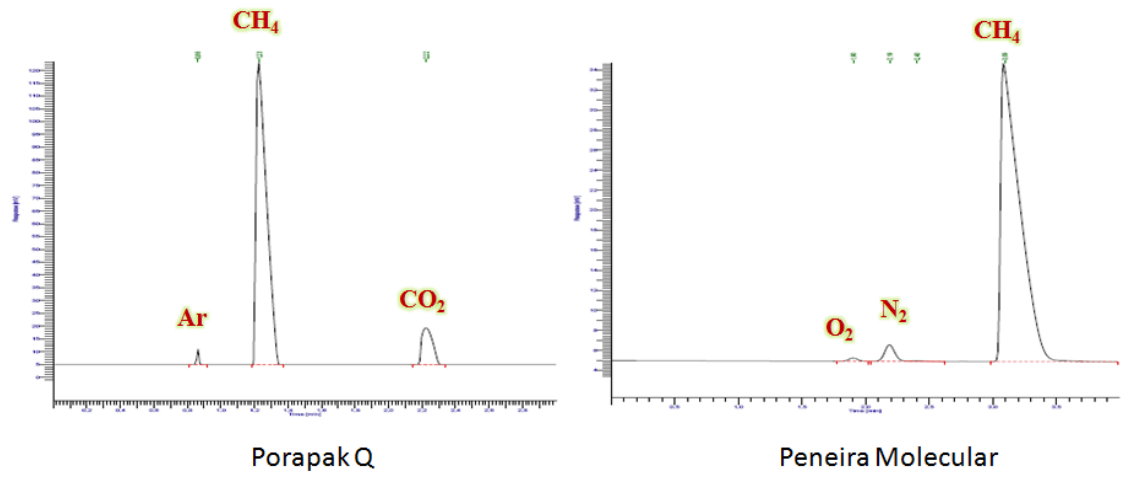

Figura 4 - Exemplos de cromatogramas gerados na décima quinta semana de experimento em $\mu \mathrm{V}$ x s. 
Volume de metano gerado: A partir dos valores das áreas dos picos obtidos na cromatografia, foi possível estimar a quantidade de metano gerada ao longo do processo. Primeiramente, dividiramse todas as áreas obtidas por fatores de resposta obtidos por Dietz (1967), necessários para se obter a resposta real das quantidades presentes no biorreator (Priebe, 2013).

Com as novas áreas obtidas, levou-se em consideração apenas o percentual entre elas. O tempo do pico não foi rigorosamente considerado devido a sua grande sensibilidade à introdução da amostra no equipamento e ao estado do septo de borracha presente no local de introdução da amostra.

Para o cálculo da porcentagem de metano, considerou-se apenas a proporção da área obtida na Porapak Q, pois o pico referente ao metano na Peneira Molecular não consegue separar eficientemente o $\mathrm{CO}_{2}$ do metano, o que acabaria amplificando esse sinal caso o percentual de metano fosse dali obtido. A Peneira Molecular serviu apenas para acompanhar a quantidade de oxigênio dentro do biorreator, que, caso não decrescesse, acusaria um possível vazamento.

Uma vez obtido o percentual de metano nos dias em que se realizou a cromatografia, estimou-se um comportamento linear entre cada um dos dias de cromatografia, e pode-se estimar o percentual de metano nos dias em que não se realizou a medida. Multiplicou-se esse percentual pelo volume de gás total obtido em cada dia e as curvas obtidas, com comportamento semelhante às curvas de gás total gerado, são mostradas na Figura 5,

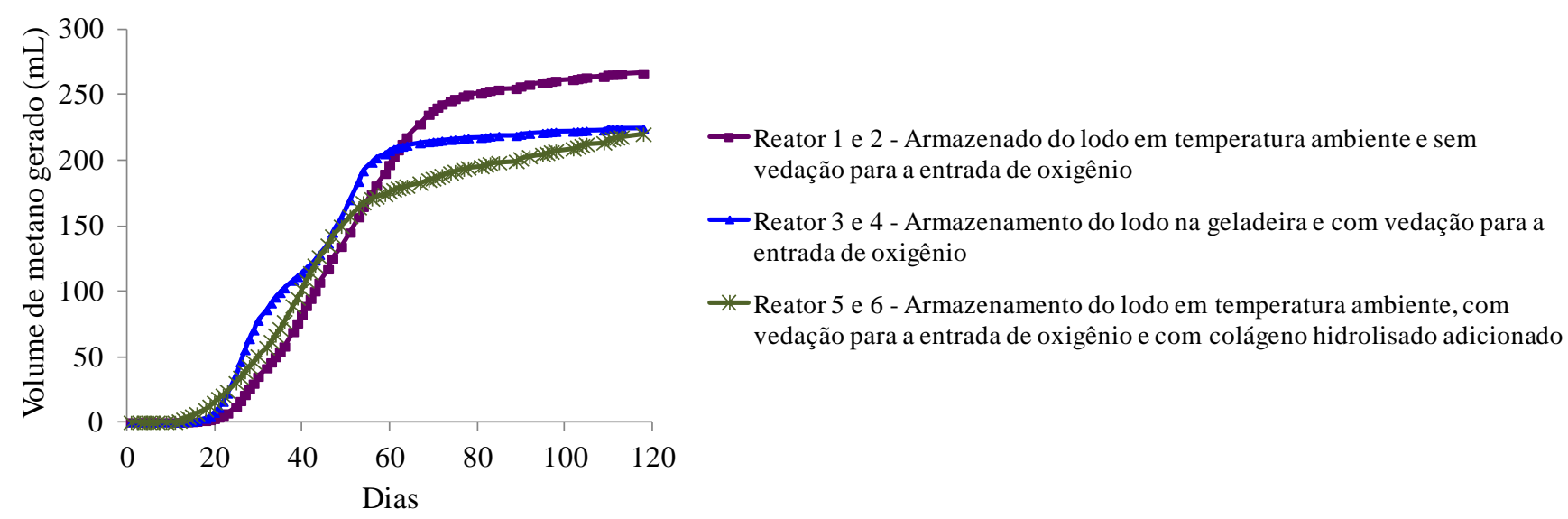

Figura 5 - Média do volume de metano gerado de cada duplicata.

\subsection{Crescimento dos microrganismos}

Após três semanas de incubação, foi observado crescimento microbiano, onde algumas unidades formadoras de colônia (UFC) são mostradas na Figura 6. A pouca quantidade de colônias após tanto tempo de cultivo mostra que o meio é bastante seletivo para os microrganismos de interesse, os metanogênicos, que apresentam crescimento lento (Whitman, 2006). Além disso, não foi observado nenhum crescimento na superfície do meio, em contato com o ar, mostrando novamente a seletividade do meio e que a presença de oxigênio não afetou o crescimento no interior do meio, 
mostrando que ele é um meio bastante redutor. Ainda, a E. coli apresentou crescimento e a $P$. aeruginosa não cresceu, dentro do esperado.

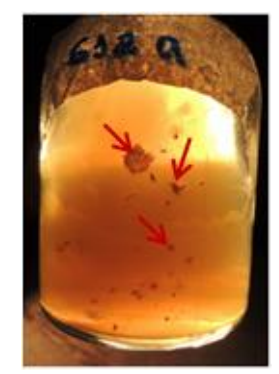

Figura 6 - Exemplo de frasco da segunda diluição (1/10.000) com amostra extraída do sólido precipitado com UFC indicadas após 3 semanas de cultivo.

A contagem média de UFC após 3 semanas de incubação resultou em $38,5.10^{5} \mathrm{UFC} / \mathrm{mL}$ da fase sólida e em $5.10^{5} \mathrm{UFC} / \mathrm{mL}$ da fase líquida do biorreator.

\section{CONCLUSÕES}

Como já comprovado por Priebe et al. (2013), o cromo não é inibidor dos microrganismos. A produção de gás, especialmente de metano, comprovada pela cromatografia, mostra que há atividade metanogênica mesmo na presença desse mineral.

A forma de armazenamento do lodo que se mostrou mais adequada, diferente do esperado, foi em temperatura ambiente sem a vedação para a entrada de $\mathrm{O}_{2}$. Acredita-se que a entrada de $\mathrm{O}_{2}$ não foi um fator que contribuiu, pois a difusão do oxigênio é ineficiente independente da temperatura, assim o lodo mantém-se em anaerobiose, condição necessária para o crescimento dos microrganismos de interesse. Já quanto a temperatura de armazenamento, acredita-se que manter os microrganismos em baixas temperaturas retardou a sua adaptação aos biorreatores.

A adição de colágeno favoreceu a adaptação dos microrganismos nos biorreatores, pois a geração de gás foi maior no início dos experimentos com esse lodo. Isso era esperado devido ao fato do colágeno puro ser mais fácil de degradar do que o presente no wet-blue. Entretanto, com o decorrer do experimento, não se mostrou a forma que mais produziu metano. O motivo disso ainda será estudado.

O método de isolamento, com relação ao ambiente anaeróbio, mostrou-se eficiente, pois não houve crescimento da $P$. aerugionosa, demonstrando a ausência de $\mathrm{O}_{2}$ disponível no frasco.

A continuidade do trabalho se dará com as seguintes mudanças no método apresentado: retirar os microrganismos na sua fase de crescimento máximo a partir de novos ensaios de biorreatores em escala de bancada, utilizar atmosfera com $\mathrm{CO}_{2}$ e $\mathrm{N}_{2}$ para assegurar ainda mais a anaerobiose e utilizar os lacres de alumínio nos frascos de penicilina desde o momento de preparação dos frascos, evitando perda de gases. Identificar os principais grupos de microrganismos isolados utilizando o método de 
PCR e sequenciamento utilizando o gene do RNA16S.

\section{AGRADECIMENTOS}

Os autores agradecem o auxílio financeiro do CNPq (Edital UNIVERSAL - MCTI/CNPq N 14/2010 e $N^{o}$ 14/2013) e da FAPERGS (Edital 04/2012 Programa Pesquisador Gaúcho - PqG e Edital FAPERGS/CAPES 17/2012 Programa de Bolsa de Desenvolvimento Tecnológico e Industrial para Centros e Laboratórios Multiusuários).

\section{REFERÊNCIAS}

BIDONE, R. F.; HARTMANN, F.; ROSA, A. L.; SOUTO, G. D. B.; POVINELLI, J. Filtros anaeróbios aplicados ao tratamento de lixiviado de aterros sanitários. In: CONGRESSO BRASILEIRO DE ENGENHARIA SANITÁRIA E AMBIENTAL, 27, 2007, Rio de Janeiro, Anais.

DETTMER, A. Seleção, isolamento e otimização dos meios de cultivo de microrganismos produtores de enzimas para aplicação ao processamento de peles na etapa de depilação/caleiro. Tese de Doutorado, UFRGS, Porto Alegre, RS, Brasil, 2012.

DIETZ, W. A. Response factors for gas chromatographic analyses. Journal of Chromatographic Science. 5 (2): 68-71, 1967.

PRIEBE, G. P. S.; MARCÍlIO, N. R.; GUSMÃO, A. L.; KIPPER, E.; GUTTERRES, M. Biogas production from leather industry wastes. In: INTERNATIONAL UNION OF LEATHER TECHNOLOGISTS AND CHEMISTS SOCIETIES, 32, 2013, Istambul, Anais.

QUADROS, A. V. Avaliação da remoção de matéria orgânica carbonácea em filtros anaeróbios tratando lixiviado de resíduos sólidos urbanos. Dissertação de Mestrado, UNISINOS, RS, Brasil, 2009.

SOUZA, M. R. F. Uso do lodo de curtume como fonte de nutrientes em plantas forrageiras. Seminário apresentado junto à Disciplina Seminários Aplicados do Programa de Pós-Graduação em Ciência Animal da Escola de Veterinária, UFG, GO, Brasil, 2009.

WHITMAN, W. B.; BOWEN T. B.; BOONE D. R. Prokaryotes. DOI: 10.1007/0-387-30743-5_9. 3:165-207, 2006. 